\title{
Abdominal versus laparoscopic hysterectomies for benign diseases: evaluation of morbidity and mortality among 465,798 cases
}

\author{
Amir Wiser • Christina A. Holcroft • Togas Tulandi • \\ Haim A. Abenhaim
}

Received: 5 November 2012 / Accepted: 20 December 2012 /Published online: 12 January 2013

(C) Springer-Verlag Berlin Heidelberg 2013

\begin{abstract}
Hysterectomy is the most common major gynecological surgery performed in women. The aim of this study was to compare major morbidity and mortality between abdominal hysterectomy $(\mathrm{AH})$ and laparoscopic hysterectomy (LH) for benign diseases. We performed a retrospective cohort study using the data from Health Cost and Utilization Project Nationwide Inpatient Sample. Women were admitted for hysterectomy for benign diseases between the years 2002 and 2008. In-hospital morbidities and mortalities were identified using the diagnostic and procedural codes classified according to the International Classification of Disease, Ninth Revision, and Clinical Modification. Logistic regression analysis was used to estimate the relationship between the type of hysterectomy and the development of major morbidity and mortality. Of a total 465,798 cases, 389,189 women $(83.6 \%)$ underwent $\mathrm{AH}$ and the remainders underwent $\mathrm{LH}(76,609$, $16.4 \%)$. The LH group was younger and more likely to be Caucasian than those who underwent AH. Although major morbidities and mortalities were rare, women who underwent LH were less likely to develop thromboembolic events ( $0.68 \%$ vs. $0.84 \%$, odds ratio (OR) $0.85(0.77-0.93)$ ), require blood transfusions $(2.4 \%$ vs. $4.7 \%$, OR $0.58(0.55-0.61))$, and sustain bowel perforation $(0.07 \%$ vs. $0.13 \%$, OR 0.56 $(0.42-0.74))$. The mortality rate was also lower in the $\mathrm{LH}$ group $(0.01 \%)$ compared with the AH group $(0.03 \%$, OR $0.48(0.24-0.95))$. Our conclusion was that for benign
\end{abstract}

\footnotetext{
A. Wiser $\cdot$ C. A. Holcroft $\cdot$ T. Tulandi $(\triangle) \cdot$ H. A. Abenhaim Department of Obstetrics and Gynecology, McGill University, 687 Pine Avenue West,

Montreal, Quebec H3A 1A1, Canada

e-mail: togas.tulandi@mcgill.ca

T. Tulandi

Centre for Clinical Epidemiology and Community Studies, Jewish General Hospital, Montreal, Quebec, Canada
}

diseases, laparoscopic hysterectomy is associated with a lower complication rate than abdominal hysterectomy. When possible, hysterectomy performed for benign diseases should be performed with minimally invasive technique.

Keywords Laparoscopic hysterectomy $\cdot$ Abdominal hysterectomy $\cdot$ Morbidity $\cdot$ Mortality

\section{Background}

Hysterectomy is the most common major gynecological surgery performed in women [1]. The majority of patients undergo hysterectomy for benign conditions including uterine leiomyoma, pelvic organ prolapse, or menorrhagia [2]. The surgical indication for hysterectomy has remained unchanged over time; however, the medical and surgical options for treatment of benign gynecological diseases have evolved considerably. The traditional approaches for hysterectomy were by laparotomy (abdominal hysterectomy $(\mathrm{AH})$ ) or vaginally [1].

Reich et al. reported the first case of total laparoscopic hysterectomy (LH) in 1989 [3]. This approach is associated with shorter hospitalization, faster recovery, and fewer postoperative infections compared to abdominal hysterectomy [4]. It appears that laparoscopic hysterectomy is preferable than abdominal hysterectomy [5,6]. The benefits of LH versus $\mathrm{AH}$ include early return to daily activities, less intraoperative blood loss, and fewer wound or abdominal wall infections [6]. The single complication that was found to be increased after laparoscopic surgery was urinary tract injury $[5,6]$. However, despite substantial evidence regarding the advantages of LH, most hysterectomies are still performed via laparotomy [2]. The purpose of our study was to compare the morbidity and mortality between abdominal and laparoscopic hysterectomies for benign diseases. 


\section{Materials and methods}

We performed a retrospective cohort study using the data from the Healthcare Cost and Utilization Project Nationwide Inpatient Sample (HCUP-NIS) from 2002 to 2008. Each annual data set contains approximately 7 million records of hospitalized patients including demographic data, discharge diagnosis, procedure codes, and vital status at discharge for each respective admission. Records included in the data sets are representative samples of approximately $20 \%$ of admissions to the US hospitals. Diagnostic and procedural codes are classified according to the International Classification of Diseases, Ninth Revision, Clinical Modification (ICD-9).

We defined our cohort as records indicating both benign diseases and hysterectomy procedures from 2002 to 2008 . Benign disease was defined as ICD-9 codes 626.2, 626.6, 626.8, and 627.0 (menorrhagia) and $218 x$ and $219 x$ (leiomyomas) in any of the 15 diagnostic variables associated with hysterectomy. All of the 15 procedure codes were examined for ICD-9 codes to define hysterectomy. Any hysterectomy was identified by codes 68.3 (subtotal abdominal hysterectomy) and 68.4 (total abdominal hysterectomy). Within the hysterectomies, the subgroup of laparoscopy procedures was defined as code 68.51 or any other laparoscopy procedure $(54.21,65.01,65.31,65.41,65.53,65.63$, or 65.64). The remaining hysterectomies were defined as abdominal hysterectomy.

Patient characteristics that were included in the analysis included age, race, income group (combined variables for median household income categories and median household income quartiles for patient's zip code which were defined in different years), insurance type (Medicare, Medicaid, private, or others), hospital type (rural, urban nonteaching, and urban teaching), and elective vs. non-elective admission (combining a type and elective variables defined in different years). Comorbidities have been incorporated in the HCUP-NIS database since 2002 and are calculated with the Agency for Healthcare Research and Quality software (www.ahrq.gov/data/hcup). We included congestive heart failure, chronic pulmonary disease, diabetes (complicated or uncomplicated), hypertension (complicated or uncomplicated), lymphoma, and peripheral vascular disorders.

We identified several hospital outcomes as potentially associated with the type of hysterectomy. Death and length of stay were available in the NIS database. The 15 diagnostic code variables were checked for any code indicating deep vein thrombosis (453.4 or V12.51), pulmonary embolism (415.1 or V12.51), acute myocardial infarction (410), bowel perforation (569.8, other specified disorders of intestine), and bladder injury (665.5, other injury to pelvic organs). Transfusion of blood and blood components was defined as any procedure code 99.0.

Descriptive statistics were used to analyze baseline characteristics among women undergoing a hysterectomy by abdominal approach and by laparoscopic approach. Logistic regression analysis was used to examine the association between hysterectomy type and each clinical outcome using odds ratios with adjustment for age, race, median household income, insurance type, hospital type, procedural elective status, and comorbidities. Analyses were conducted using SAS statistical software (SAS Enterprise, Cary, NC, USA). Ethical approval for the use of the data set was obtained from the Director of Professional Services of Jewish General Hospital in keeping with the provincial requirements for the use of hospital databases.

\section{Findings}

A total of 465,798 women in the HCUP-NIS database underwent hysterectomy for benign diseases between 2002 and 2008. This includes 389,189 (83.6 \%) women who underwent $\mathrm{AH}$ and 76,609 (16.4\%) who underwent LH.

Figure 1 shows a linear reduction in the total number of hysterectomies performed from 2002 to 2008. In 2002, almost 80,000 hysterectomies were included in the database compared to less than 60,000 in 2008 , a decrease of more than $30 \%$. The decrease was noted in the rate of AH only; although the rate of LH vs. AH increased, the total number of $\mathrm{LH}$ procedures remains almost constant.

The baseline characteristics of the women are summarized in Table 1. The proportion of younger women $(<35$ years of age) in the LH group was higher compared to the $\mathrm{AH}$ group (11\% vs. $8 \%$, respectively). The proportion of Caucasian women was also higher among the LH group, while women identified as African-American were more likely to have an $\mathrm{AH}$ procedure.

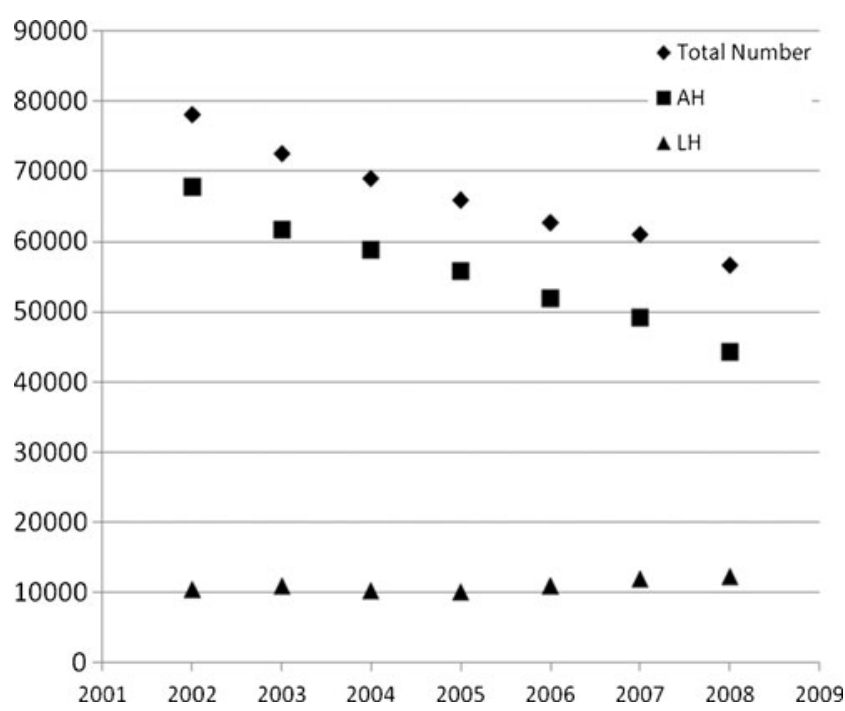

Fig. 1 Number of inpatient abdominal and laparoscopic hysterectomies between the years 2002 and 2008 in the USA 
Table 1 Baseline characteristics of 465,798 patients who underwent laparoscopic vs. abdominal hysterectomies for benign disease
${ }^{\mathrm{a}}$ Missing comorbidity data in 5,324 records

\begin{tabular}{|c|c|c|}
\hline Baseline characteristic & $\begin{array}{l}\text { Abdominal hysterectomy } \\
(n=389,189)\end{array}$ & $\begin{array}{l}\text { Laparoscopic hysterectomy } \\
(n=76,609)\end{array}$ \\
\hline \multicolumn{3}{|l|}{ Age (year) } \\
\hline$<35$ & $29,792(8 \%)$ & $8,107(11 \%)$ \\
\hline $35-39$ & $56,658(15 \%)$ & $12,295(16 \%)$ \\
\hline $40-44$ & $106,817(27 \%)$ & $19,256(25 \%)$ \\
\hline $45-49$ & $110,282(28 \%)$ & $20,301(27 \%)$ \\
\hline$\geq 50$ & $85,399(22 \%)$ & $16,606(22 \%)$ \\
\hline \multicolumn{3}{|l|}{ Race } \\
\hline Caucasian & $170,001(44 \%)$ & $43,174(56 \%)$ \\
\hline African-American & $62,291(16 \%)$ & $5,963(8 \%)$ \\
\hline Hispanic & $31,295(8 \%)$ & $4,569(6 \%)$ \\
\hline Others & $17,100(4 \%)$ & $2,627(3 \%)$ \\
\hline Unknown & $108,492(28 \%)$ & $20,276(26 \%)$ \\
\hline \multicolumn{3}{|l|}{ Median income (US\$) } \\
\hline$<35,000$ & $95,202(24 \%)$ & $15,921(21 \%)$ \\
\hline $35,000-44,999$ & $97,967(25 \%)$ & $19,278(25 \%)$ \\
\hline$\geq 45,000$ & $187,998(48 \%)$ & $39,707(52 \%)$ \\
\hline \multicolumn{3}{|l|}{ Insurance type } \\
\hline Medicare & $21,399(6 \%)$ & $3,668(5 \%)$ \\
\hline Medicaid & $34,267(9 \%)$ & $5,207(7 \%)$ \\
\hline Private & $304,072(78 \%)$ & $63,140(82 \%)$ \\
\hline Others & $28,726(7 \%)$ & $4,456(6 \%)$ \\
\hline \multicolumn{3}{|l|}{ Hospital type } \\
\hline Rural & $50,239(13 \%)$ & $10,455(14 \%)$ \\
\hline Urban, non-teaching & $177,299(46 \%)$ & $36,546(48 \%)$ \\
\hline Urban, teaching & $161,324(41 \%)$ & $29,570(39 \%)$ \\
\hline \multicolumn{3}{|l|}{ Admission } \\
\hline Elective & $338,668(87 \%)$ & $48,453(12 \%)$ \\
\hline Non-elective & $68,361(89 \%)$ & $7,898(10 \%)$ \\
\hline \multicolumn{3}{|l|}{ Comorbidities $^{\mathrm{a}}$} \\
\hline Congestive heart failure & $1,539(0.4 \%)$ & $125(0.2 \%)$ \\
\hline Chronic pulmonary disease & $26,585(7 \%)$ & $5,100(7 \%)$ \\
\hline Diabetes & $21,998(6 \%)$ & $3,159(4 \%)$ \\
\hline Hypertension & $79,065(20 \%)$ & $12,028(16 \%)$ \\
\hline Lymphoma & $265(0.07 \%)$ & $40(0.05 \%)$ \\
\hline Peripheral vascular disorder & $499(0.1 \%)$ & $68(0.09 \%)$ \\
\hline
\end{tabular}

The mode of hysterectomy and the risks of major mortality and morbidity rates are listed in Table 2. Overall, the rates of complications were very low. Even so, the patients who underwent LH had lower morbidity (deep vein thrombosis, pulmonary embolism, requirement for blood transfusion, and acute myocardial infarction) as well as less mortality compared to women in the $\mathrm{AH}$ group.

\section{Discussion}

The most common approach for hysterectomy is the open abdominal hysterectomy [1]. Compared to AH, our study shows lower morbidity and mortality after minimally invasive approach with LH even after adjusting for age, race, median household income, insurance type, hospital type, procedural elective status, and comorbidities.

Figure 1 shows a decrease in the number of hysterectomies for benign diseases of more than $30 \%$ from 2002 to 2008 . This has been described in other studies [4, 7]. The decline is probably in part due to an increase in alternative medical treatments such as the levonogestrel IUD [4, 8] and minimally invasive procedures such as endometrial ablation [4]. More recent procedures include magnetic resonance-guided focused ultrasound and uterine artery embolization. These procedures are performed as outpatient interventional radiologic treatment 
Table 2 Effect of hysterectomy approach on the risk of major morbidities and mortality

\begin{tabular}{|c|c|c|c|c|}
\hline Outcome & Abdominal hysterectomy & Laparoscopic hysterectomy & OR $(95 \% \mathrm{CI})$ & $P$ value \\
\hline DVT & $2,879(0.74 \%)$ & $502(0.66 \%)$ & $0.88(0.80-0.96)$ & 0.04 \\
\hline $\mathrm{PE}$ & $3,099(0.8 \%)$ & $522(0.68 \%)$ & $0.85(0.77-0.93)$ & 0.006 \\
\hline DVT or PE & $3,281(0.84 \%)$ & $529(0.69 \%)$ & $0.48(0.24-0.95)$ & 0.0004 \\
\hline Blood transfusion & $18,124(4.7 \%)$ & $1,805(2.4 \%)$ & $0.56(0.42-0.74)$ & 0.0001 \\
\hline Bowel perforation & $490(0.13 \%)$ & $52(0.07)$ & N/A & 0.0001 \\
\hline Bladder injury & $17(<0.01 \%)$ & $0(0 \%)$ & $0.29(0.27-0.31)$ & N/A \\
\hline Acute MI & $133(0.03 \%)$ & $13(0.02 \%)$ & $0.58(0.55-0.61)$ & 0.2 \\
\hline Length of stay $>6$ days & $15,917(4.1 \%)$ & $804(1.1 \%)$ & $0.29(0.27-0.31)$ & 0.0001 \\
\hline Death & $123(0.03 \%)$ & $9(0.01 \%)$ & $0.69(0.39-1.2)$ & 0.036 \\
\hline
\end{tabular}

$D V T$ deep vein thrombosis, $P E$ pulmonary embolism, $M I$ myocardial infarction, $N / A$ not available

of uterine leiomyomas, which can replace the traditional hysterectomy for the management of fibroid-related symptoms. These non-invasive alternatives are especially beneficial for women who prefer to avoid hysterectomy, as well as for those with high surgical risks [9]. All these non-surgical options offer alternatives to women with benign diseases.

One of the most important elements of our study was to define the study population as patients who underwent hysterectomy specifically for benign diseases. We chose to exclude patients who underwent hysterectomy for malignant disease since those patients are at higher risk of adverse outcome. They undergo more complicated hysterectomy due to the lymph node sampling and higher risk for DVT [10]. To ensure that only patients with benign disease would be included, we chose the diagnosis codes of leiomyomas and menorrhagias since these are the most common benign indications for hysterectomy. This method of selection of patients with benign disease has preliminarily been described [11]. These inclusion criteria ensured a specific patient population that would allow us to analyze the operative complications without the potential bias of hysterectomies performed for malignancy.

We found that the patients in the LH group had fewer complications (Table 2). These findings of decreased complication rates after $\mathrm{LH}$ concur with all major recent metaanalyses $[1,5,6,12,13]$. The only significant complication that was described in some studies as more prominent in $\mathrm{LH}$ patients compared to $\mathrm{AH}$ was urinary tract injuries. The last Cochrane database [6] reviewed 34 randomized trials and found a higher rate of urinary tract injuries after LH. In contrast Brummer et al. [12] described a lower rate of urinary tract injuries in $\mathrm{LH}$ patients compared to $\mathrm{AH}$ patients. Our large study confirmed the findings of Brummer et al. and also showed that the rate of bladder injury as well as bowel injury was lower among the LH group.

Other major complications, deep vein thrombosis, and pulmonary embolism (PE) were also lower in patients who underwent LH. Immobility is a known risk factor for DVT and PE [14], and short hospitalization was described as beneficial in preventing PE [15]. The LH group had a significantly shorter length of stay in the hospital (Table 2) which may explain the lower rate of DVT and PE. However, this shorter length of stay in the hospital could be a bias. The "postoperative" period for DVT and PE is not well defined, neither for diagnosis of these complication nor for prophylaxis [10]. It ranges in different studies, for prophylaxis from $24 \mathrm{~h}$ up to 5 days or until discharge, and for diagnosis from 30 until 42 days postoperation [10]. It is possible that women in the LH groups had a DVT or PE after discharge and were diagnosed as outpatients; in such cases, these patients would not be included as a complication of the LH procedure. Since the LH group had shorter length of stay, it could be that more patients were diagnosed as outpatient cases and decrease the real number of PE and DVT cases.

Our study has several limitations. First, our data does not contain information about the extent of pathology which can affect the type of the surgery and the possible complications. A very large myoma, for example, could be a technical limitation of laparoscopic intervention or be associated with a higher rate of complications during the procedure. Therefore, it could be argued that the patients who underwent LH are "easier" cases compared to the AH patients. In a large registry of 3,139 patients undergoing uterine artery embolization, the investigators noted that the presence of five or more myomas was more commonly observed among African-American women as compared to Caucasians (37\% vs. $28 \%$ ) [16]. Abenhaim et al. [11] showed that AfricanAmericans were less likely to undergo LH as compared with Caucasians, based on the same database from the years 1998 to 2002. Our study shows a similar trend in the years 20022008; the rate of African-Americans who underwent $\mathrm{AH}$ was double the rate of patients who underwent LH (16\% vs. $8 \%$, respectively). It is possible that the higher rate of African-American women in the AH group of our study 
reflects more difficult cases with larger leiomyomas and could in part explain the higher complication rate among the $\mathrm{AH}$ group.

An additional limitation is the procedural coding, which does not enable us to identify women who started initially with laparoscopic approach and were converted to laparotomy. Although this would probably be more likely in difficult cases, we hypothesize that this has a minor confounding effect only, since the overall conversion rate has been estimated at approximately $8 \%$ [17]. While this rate of conversion was published in 2005, we believe that at this time, given advanced proficiency after the period of learning curve, it is likely to be even lower. Another potential limitation is the lack of information on important potential confounding variables such as obesity. Obesity has been shown to be associated with both socioeconomic class and surgery performed [18]. We do not have the data regarding patients' BMI, and it is possible that the AH group had more obese patients and as a result higher complication rate. It is also possible, however, that this confounder would shift the effect towards more laparascopic cases as it is believed by many that in obese women, a laparoscopic approach is easier.

In our study, we did not have the data about vaginal hysterectomy $(\mathrm{VH})$ to compare between all three options of hysterectomy for benign disease. Brummer et al. [12] reported that $\mathrm{VH}$ was the most common hysterectomy performed, at $44 \%$ of patients with benign disease in Finland. $\mathrm{LH}$ and $\mathrm{VH}$ comprised $76 \%$ of the national operations. No significant differences in major complications were found between these two approaches. A major complication will occur in $3-4 \%$ of patients, and $\mathrm{VH}$ is also considered as a safe option for hysterectomy.

However, our study has a number of strengths. First, it is a population-based sample of all US admissions. This important aspect of our study population allows appropriate generalizations to balance any confounder that could be encountered such as economic, racial, and ethnic differences. Data analyzed in this study is less than 10 years old (2002-2008) and thus reflects the current standard of care. This study is the largest study that can reflect the era following the learning curve associated with laparoscopic hysterectomy [8]. Finally, the data sample is extremely large allowing us to identify important associations in rare outcomes such as death and acute myocardial infarction that would perhaps not be able to be detected in a smaller, singlecenter experience study.

\section{Conclusion}

In conclusion, $\mathrm{AH}$ and $\mathrm{LH}$ performed for benign diseases are procedures with low complication rates. LH appears to be associated with a lower complication rate than $\mathrm{AH}$ as well as a lower overall mortality. Our findings suggest that, when possible, surgeons should be encouraged to consider $\mathrm{LH}$ over AH for benign diseases.

Conflict of interest The authors report no conflict of interest. The authors alone are responsible for the content and writing of the paper.

\section{References}

1. Warren L, Ladapo JA, Borah BJ, Gunnarsson CL (2000) Open abdominal versus laparoscopic and vaginal hysterectomy: analysis of a large United States payer measuring quality and cost of care. J Minim Invasive Gynecol 16:581-588

2. Wu JM, Wechter ME, Geller EJ, Nguyen TV, Visco AG (2007) Hysterectomy rates in the United States, 2003. Obstet Gynecol 110:1091-1095

3. Reich H (1992) Laparoscopic hysterectomy. Surg Laparosc Endosc 2:85-88

4. Candiani M, Izzo S (2010) Laparoscopic versus vaginal hysterectomy for benign pathology. Curr Opin Obstet Gynecol 22:304-308

5. Johnson N, Barlow D, Lethaby A, Tavender E, Curr L, Garry R (2005) Methods of hysterectomy: systematic review and meta-analysis of randomised controlled trials. BMJ $330: 1478$

6. Nieboer TE, Johnson N, Lethaby A, Tavender E, Curr E, Garry R et al (2009) Surgical approach to hysterectomy for benign gynaecological disease. Cochrane Database Syst Rev 3:CD003677

7. Brummer TH, Jalkanen J, Fraser J, Heikkinen AM, Kauko M, Makinen J et al (2009) FINHYST 2006-national prospective 1-year survey of 5,279 hysterectomies. Hum Reprod 24:25152522

8. Vilos GA, Marks J, Tureanu V, Abu-Rafea B, Vilos AG (2011) The levonorgestrel intrauterine system is an effective treatment in selected obese women with abnormal uterine bleeding. J Minim Invasive Gynecol 18:75-80

9. Sasa H, Kaji T, Furuya K (2012) Indications and outcomes of uterine artery embolization in patients with uterine leiomyomas. Obstet Gynecol Int 2012:920831

10. Einstein MH, Pritts EA, Hartenbach EM (2007) Venous thromboembolism prevention in gynecologic cancer surgery: a systematic review. Gynecol Oncol 105:813-819

11. Abenhaim HA, Azziz R, Hu J, Bartolucci A, Tulandi T (2008) Socioeconomic and racial predictors of undergoing laparoscopic hysterectomy for selected benign diseases: analysis of 341487 hysterectomies. J Minim Invasive Gynecol 15:11-15

12. Brummer TH, Jalkanen J, Fraser J, Heikkinen AM, Kauko M, Makinen J et al (2011) FINHYST, a prospective study of 5279 hysterectomies: complications and their risk factors. Hum Reprod 26:1741-1751

13. Kluivers KB, Ten Cate FA, Bongers MY, Brölmann HA, Hendriks JC (2011) Total laparoscopic hysterectomy versus total abdominal hysterectomy with bilateral salpingo-oophorectomy for endometrial carcinoma: a randomised controlled trial with 5-year follow-up. Gynecol Surg 8:427-434 
14. Brasileiro AL, Miranda F Jr, Ettinger JE, Castro AA, Pitta GB, de Moura LK et al (2008) Incidence of lower limbs deep vein thrombosis after open and laparoscopic gastric bypass: a prospective study. Obes Surg 18:52-57

15. Cotter SA, Cantrell W, Fisher B, Shopnick R (2005) Efficacy of venous thromboembolism prophylaxis in morbidly obese patients undergoing gastric bypass surgery. Obes Surg 15:1316-1320

16. Myers ER, Goodwin S, Landow W, Mauro M, Peterson E, Pron $G$ et al (2005) Prospective data collection of a new procedure by a specialty society: the FIBROID registry. Obstet Gynecol 106:44-51

17. Leonard F, Chopin N, Borghese B, Fotso A, Foulot H, Coste $\mathrm{J}$ et al (2005) Total laparoscopic hysterectomy: preoperative risk factors for conversion to laparotomy. J Minim Invasive Gynecol 12:312-317

18. Hakim RB, Benedict MB, Merrick NJ (2004) Quality of care for women undergoing a hysterectomy: effects of insurance and race/ ethnicity. Am J Public Health 94:1399-1405 